\title{
Short and Long-Term Efficacy of Laparoscopic Ovarian Diathermy in Women with Polycystic Ovary Syndrome
}

\section{Eficácia a Curto e Longo Prazo da Electrocoagulação Laparoscópica dos Ovários em Mulheres com Síndrome dos Ovários Poliquísticos}

\author{
Rita LUZ $\bigotimes^{1}$, Joana BARROS², Ana AGUIAR², Cátia RODRIGUES², Ana Paula SOARES², Joaquim NUNES², \\ Sandra SOUSA ${ }^{2}$, Carlos CALHAZ-JORGE ${ }^{2}$
}

Acta Med Port 2016 Jul-Aug;29(7-8):441-448 - http://dx.doi.org/10.20344/amp.6377

\section{ABSTRACT}

Introduction: Polycystic ovary syndrome is the most frequent cause of anovulatory infertility and management involves a multistep approach. Laparoscopic ovarian diathermy is accepted as a second-line treatment of patients who failed to respond to clomiphene citrate. The aims of this study were to determine the efficacy of this technique at short and long-term and to perform an analysis of predictive factors of spontaneous pregnancy.

Material and Methods: This retrospective study involved 76 women who underwent laparoscopic ovarian diathermy between 2004 and 2013 in a university hospital. Main outcomes were cycle regularity and pregnancy. Short-term outcomes recorded during followup in our centre were reviewed and long-term outcomes were evaluated by a telephone interview to all women whose surgery was undertaken more than three years ago. Clinical and biochemical data were analysed as predictive factors of spontaneous conception in patients without other infertility factors.

Results: Menstrual cycle regularity was initially achieved in 53 (70\%) women and in the long-term follow-up subgroup, 52\% (12/23) had regular periods. In general, 53 (70\%) women conceived and 77 pregnancies were achieved, $60 \%$ of which were spontaneous. The only prognostic factor found to be significantly associated with spontaneous conception was a shorter duration of infertility (< 3 years) $(p<0.05)$.

Discussion: Laparoscopic ovarian diathermy showed pregnancy rates comparable to other ovulation induction treatments with the advantage of having a long lasting beneficial effect in menstrual regularity and fertility.

Conclusion: Laparoscopic ovarian diathermy is a safe and effective treatment option for anovulatory infertility in women with polycystic ovary syndrome.

Keywords: Anovulation; Diathermy; Infertility, Female; Laparoscopy; Polycystic Ovary Syndrome; Treatment Outcome.

\section{RESUMO}

Introdução: A síndrome dos ovários poliquísticos é a causa mais frequente de anovulação e o tratamento envolve uma abordagem faseada. A electrocoagulação laparoscópica dos ovários é aceite como segunda linha no tratamento das doentes que não respondem ao citrato de clomifeno. Os objectivos deste estudo foram determinar a eficácia desta técnica a curto e longo prazo e definir os factores preditivos de gravidez espontânea.

Material e Métodos: Este estudo retrospectivo envolveu 76 mulheres submetidas a electrocoagulação dos ovários entre 2004 e 2013 , num hospital universitário. Os desfechos principais foram a regularidade menstrual e gravidez. Os resultados a curto prazo registados durante a vigilância na unidade foram revistos e os desfechos a longo prazo foram avaliados através de entrevista telefónica realizada a todas as mulheres operadas há mais de três anos. Dados clínicos e bioquímicos foram analisados como factores preditivos de gravidez espontânea em doentes sem outros factores de infertilidade.

Resultados: A regularidade do ciclo menstrual foi alcançada inicialmente em 53 (70\%) mulheres e a longo prazo, 52\% (12/53) tinham ciclos regulares. Em geral, $53(70 \%)$ mulheres engravidaram e foram obtidas 77 gravidezes, $60 \%$ das quais foram espontâneas. 0 único factor de prognóstico associado a gravidez espontânea foi a duração da infertilidade inferior a três anos $(p<0,05)$.

Discussão: A electrocoagulação dos ovários demonstrou taxas de gravidez comparáveis a outros tratamentos de indução da ovulação com a vantagem de ter efeitos benéficos duradouros na regularidade menstrual e fertilidade.

Conclusão: A electrocoagulação dos ovários é uma opção de tratamento segura e eficaz na infertilidade anovulatória em mulheres com síndrome dos ovários poliquísticos.

Palavras-chave: Anovulação; Diatermia; Infertilidade Feminina; Laparoscopia; Síndrome do Ovário Poliquístico; Resultado do Tratamento.

\section{INTRODUCTION}

Polycystic ovary syndrome (PCOS) is a complex and heterogeneous disease of unknown etiology, characterized by disturbances at the reproductive and metabolic level. The cardinal features are summarized by the Rotterdam diagnostic criteria: hyperandrogenism, oligo- or anovulation and polycystic ovaries. ${ }^{1}$ Part of this syndrome complexity

is due to the broad spectrum of manifestations that include from irregular menses to amenorrhea and infertility, mild to severe forms of hirsutism, acne and female-pattern alopecia, normal weight to obesity, insulin resistance and metabolic syndrome. ${ }^{2}$ The prevalence of PCOS varies between $6 \%-8 \%$ if the 1990 National Institutes of Health/

1. Serviço de Ginecologia e Obstetrícia. Centro Hospitalar de Setúbal. Setúbal. Portugal.

2. Departamento de Obstetrícia, Ginecologia e Medicina da Reprodução. Hospital de Santa Maria. Centro Hospitalar Lisboa Norte. Lisboa. Portugal.

$\square$ Autor correspondente: Rita Luz. rita.luz@gmail.com

Recebido: 09 de março de 2015 - Aceite: 09 de novembro de 2015 | Copyright @ Ordem dos Médicos 2016 
National Institute of Child Health and Human Disease (NIH/ $\mathrm{NICHD)} \mathrm{criteria} \mathrm{are} \mathrm{used,} \mathrm{but} \mathrm{can} \mathrm{be} \mathrm{two} \mathrm{to} \mathrm{three} \mathrm{times}$ higher if definition is based on the revised 2003 Rotterdam criteria. $^{3-5}$

PCOS is the most frequent cause of anovulatory infertility ${ }^{6,7}$ and anovulation is frequently the only cause of infertility in women with PCOS; however a basic evaluation of the couple should always be undertaken. Treatment usually involves a multistep approach, starting with lifestyle changes and progressing to ovulation induction, followed by surgery and assisted reproductive techniques. ${ }^{8,9}$

Lifestyle changes, diet and exercise should be considered before medical treatment in overweight and obese patients as it has been shown to improve ovulation and pregnancy rates and improve the endocrine profile. Ovulation induction with clomiphene citrate is usually the first-line medical treatment and studies have shown an ovulation rate of $60-85 \%$ and a pregnancy rate of $30 \%-50 \%$ after six ovulatory cycles with a multiple pregnancy risk of less than $7 \% .{ }^{9}$ Nevertheless, clomiphene citrate resistance is common and occurs in $15 \%$ to $40 \%$ of women. ${ }^{10}$ For this subgroup of patients alternative treatments are given. Metformin can improve ovulation and pregnancy rates particularly if administrated with clomiphene citrate. Gonadotrophin ovulation induction is an effective alternative but it is an expensive option that requires intensive surveillance and encompasses a high risk of hyperstimulation syndrome and multiple pregnancy. ${ }^{8-10}$ Letrozole is an aromatase inhibitor that was recently found to be associated with a higher livebirth and ovulation rate in comparison with clomiphene citrate. ${ }^{11}$

The first surgical treatment of women with PCOS was proposed by Stein and Leventhal in 1935. The procedure involved an ovarian wedge resection by laparotomy and the initial reports showed promising ovulation and pregnancy rates. The procedure was abandoned due to the risk of premature ovarian failure and frequent pelvic adhesions. ${ }^{12}$ In 1984, a less invasive modification of the classic procedure was described by Gjønnæss. ${ }^{13}$ Laparoscopic ovarian drilling or diathermy (LOD) is currently accepted as a second-line treatment in clomiphene resistant women. The mechanism of action is poorly understood. By using diathermy or laser vaporisation to make four to ten holes on the ovary, the ovarian androgen-producing tissue is destroyed, leading to local and systemic endocrine changes that are thought to improve follicular maturation and ovulation. ${ }^{14}$ At 6 months, the spontaneous ovulation and pregnancy rates can be as high as $76 \%$ and $56 \%$, respectively. ${ }^{12}$ Compared to gonadotropin treatment, LOD is as effective and has a lower risk of multiple pregnancies and hyperstimulation syndrome, does not require careful monitoring, is a one-time treatment and has an inferior cost. ${ }^{15,16}$ The disadvantages are the need for general anaesthesia, risks of laparoscopy and pelvic adhesion formation and the rare risk of ovarian destruction leading to ovarian failure. ${ }^{12}$ Long-term follow-up studies for up to ten years suggest that sustained improvements in menstrual regularity and ongoing fertility can be achieved in a proportion of cases. ${ }^{17,18}$

About 20\% - 30\% women fail to respond to LOD and the exact cause of failure in some patients remains uncertain. Identifying predictive factors of success could help in selecting women who could benefit more from this surgical treatment and improve success rates.

The aim of this study was to determine the efficacy of LOD in patients with PCOS anovulatory infertility in our population. The primary outcome was pregnancy rate and the secondary outcome was menstrual regularity, both at short and long-term. In a subgroup of patients in which other causes of infertility were excluded, an analysis of predictive factors of spontaneous pregnancy was performed.

\section{MATERIAL AND METHODS}

This study was conducted at Centro Hospitalar Lisboa Norte-Hospital de Santa Maria, a university hospital. Initially, data from 84 infertile women with PCOS who underwent LOD over a 10-year period from 2004 - 2013 was reviewed. PCOS was defined based on the Rotterdam criteria. ${ }^{1}$ Eight cases were excluded from analysis because they were lost for follow-up immediately after surgery. Most patients were previously treated unsuccessfully with clomiphene citrate and many had received several other forms of treatment - ovulation induction with gonadotrophins (49), intrauterine insemination (3) and in vitro fertilization (2).

A standard information sheet was used to register clinical and anthropometrical characteristics upon first appointment in our centre. Clinical data included age, origin, age of menarche, regularity of the menstrual cycle, type and duration of infertility, previous pregnancies and deliveries, signs of clinical hyperandrogenism (acne or hirsutism) and smoking habits. Anthropometric characteristics included blood pressure, weight and height. Hypertension was defined by a repeatedly elevated blood pressure (above $140 / 90 \mathrm{mmHg}$ ) or by the need of anti-hypertensive drugs. Body mass index was calculated and classified according to the World Health Organization (WHO) classification. ${ }^{19}$ Biochemical and hormone blood tests included fasting plasma glucose, cholesterol, triglycerides, thyroidstimulating hormone (TSH), follicle-stimulating hormone (FSH), luteinizing hormone (LH), LH/FSH ratio, estradiol, free and total testosterone and free androgen index. Prolactine, sex hormone binding globulin and 17-hydroxyprogesterone were evaluated in order to exclude other causes. A 2-hour oral glucose tolerance test was also carried out. Diabetes, impaired glucose tolerance and impaired fasting tolerance were defined using the WHO criteria. ${ }^{20}$ Dyslipidemia was defined as elevated levels of total cholesterol (>180 mg/ $\mathrm{dL}$ ), low-density lipoprotein (> $100 \mathrm{mg} / \mathrm{dL}$ ) or triglycerides (> $150 \mathrm{mg} / \mathrm{dL}$ ) or low levels of high-density lipoprotein (< $45 \mathrm{mg} / \mathrm{dL}$ ). Biochemical hyperandrogenism was diagnosed if there were high levels of total testosterone (> $150 \mathrm{ng} / \mathrm{dL})$, free testosterone (> $2.57 \mathrm{pg} / \mathrm{mL}$ ) or free androgen index (> 9.3). An ultrasound scan was performed in most patients to exclude other pathologies and assess ovary morphology and volume. A spermogram was requested to all partners 
and other infertility factors were recorded.

Laparoscopic ovarian diathermy was performed under general anaesthesia and involved a three port laparoscopy: a $10 \mathrm{~mm}$ umbilical port and two $5 \mathrm{~mm}$ ports on the lower left and right abdominal quadrants. Chromotubation with methylene blue dye to assess tubal patency was performed in all patients prior to drilling. A diathermy needle with monopolar current was applied to perform 6 to 10 punctures on the ovary.

Follow-up comprised a first appointment to evaluate post-operative recovery and eventual complications and a 3-month follow-up to assess regularity of menstrual cycles. Duration of follow-up was defined as the interval between surgery and conception or last appointment. Biochemical tests to evaluate spontaneous ovulation were not performed and many women did not have a reliable temperature chart. If the women failed to conceive after a period of time, other treatments were offered. The interval between LOD and initiation of other treatments was decided based on regularity of cycles, concomitant infertility factors, infertility duration and woman's age. Reproductive outcomes assessed included pregnancy rate, method of conception, pregnancy outcomes, multiple pregnancies and live-birth rate. Short-term outcomes were recorded during follow-up in our centre until pregnancy was achieved or the couple no longer desired to pursue fertility treatment and were reviewed in February 2014. Long-term outcomes were evaluated by a telephone interview to all women whose surgery was undertaken more than three years ago, performed between March and June 2014. Questions aimed to obtain information about regularity of the menstrual cycle and new pregnancies, method of conception and outcome. Out of the 58 eligible women, 46 responded.

Evaluation of predictive factors of spontaneous conception of the first post-treatment pregnancy was performed in a group of patients. Patients excluded from this analysis had bilateral tubal occlusion, abnormal sperm analysis and severe endometriosis. The subgroup of patients in which their first pregnancy was spontaneous and occurred during follow-up in our centre (27) was compared to the remaining cases with no pregnancy or conception after other infertility treatments (43). Analyses included clinical, anthropometric and biochemical data.

Statistical Package for Social Sciences (SPSS) 17.0 was used for data analyses. Continuous variables were tested for normality and expressed as mean (standard deviation) or median (interquartile range), accordingly. Comparison was performed using independent sample $t$-test for normally distributed data and Mann-Whitney $U$ when distribution was not normal. Categorical variables were represented as percentages and compared with Chi-square or Fischer's exact tests. Related samples were compared with Wilcoxon signed-rank test. Some variables were not available for the all cohort and are identified if total number is stated.

\section{RESULTS}

Clinical, anthropometric and biochemical characteristics of the 76 patients included are summarized in Table 1. The majority of women $(75 \%)$ had primary infertility and $21(28 \%)$ were trying to conceive for more than three years. Other concomitant factors of infertility were found in 14 cases (2 bilateral tubal occlusion, 1 case of stage IV endometriosis, 8 cases of mild uterine malformation and 3 partners with a subfertile male factor). Most women (49, $64 \%)$ had oligomenorrhea and $16(21 \%)$ had secondary amenorrhea. Twenty-three women $(30 \%)$ had acne and/ or hirsutism and $16(33 \%)$ biochemical evidence of hyperandrogenism. Thirty-eight $(38 / 51 ; 75 \%)$ women had at least one ovary with increased ovarian volume ( $>10$ $\mathrm{mL}$ ) and in 25 (25/50; 50\%) LH/FSH ratio was elevated (> 2). Evaluation of comorbidities frequently associated with PCOS revealed that 36 (47\%) women were overweight or obese, 31 (31/43; 72\%) had dyslipidemia, 2 (2/38; 5.3\%) had impaired glucose tolerance and one was hypertensive.

Laparoscopic ovarian diathermy was bilateral except in four cases. In three cases only one ovary showed polycystic features and concerns regarding excessive diathermy damage to a macroscopically normal ovary was the reason for unilateral LOD. In the fourth patient, one ovary was surrounded by dense adhesions and to proceed with LOD was judged to result in unacceptable surgical risk. Positive findings on laparoscopy were pelvic adhesions in $15(20 \%)$, stage I to IV endometriosis in $28(37 \%)$, ovarian cyst in six (7.9\%), unilateral and bilateral tubal occlusion in $15(20 \%)$ and two $(2.6 \%)$ women, respectively. Other laparoscopic procedures performed at the same time included adhesiolysis and/or cystectomy in 15 patients. Seven (9.2\%) patients underwent concomitant hysteroscopy to evaluate the endometrial cavity and in four of these a septoplasty was performed. There were no records of immediate or late complications.

Patients were followed in our centre for a median of 7 months $(4.3-20)$. The three month assessment of the menstrual cycle revealed that $53(70 \%)$ women had regular cycles, $17(22 \%)$ had irregular cycles and six $(7.9 \%)$ had oligo- or amenorrhea. In the long-term follow-up subgroup, menstrual cycle regularity was analysed in the 23 women that did not use any form of hormonal contraception and $12(12 / 23 ; 52 \%)$ had regular cycles, seven $(7 / 23 ; 31 \%)$ had irregular cycles and four had oligo- or amenorrhea (4/23; $17 \%)$. Fig. 1 represents the changes in menstrual cycle characteristics throughout time.

Table 2 shows reproductive outcomes in three periods after surgery. In general, 53 (70\%) women conceived and 24 (32\%) conceived more than once during the overall followup period, giving a total of 77 pregnancies. In 29 (38\%) women first pregnancy was spontaneous and in general more than half of pregnancies were spontaneous (46/77; $60 \%)$. The median interval to first conception after surgery was six months $(3-20)$ and to first spontaneous pregnancy was three months $(2-7)$. Considering all pregnancies, 49 couples $(64 \%)$ had a conception leading to live birth. Overall, miscarriage rate was $21 \%(16 / 77)$, higher in the women that conceived after in vitro fertilization or intracytoplasmatic 
Table 1 - Clinical, anthropometrical and biochemical preoperative characteristics

\begin{tabular}{|c|c|c|}
\hline Characteristic (units and/or $n^{*}$ ) & Mean or Median or Number & Standard deviation or Interquartile range or Percentage \\
\hline Age at surgery (years) & 30.0 & \pm 4.1 \\
\hline \multicolumn{3}{|l|}{ Origin } \\
\hline Caucasian & 37 & $48.7 \%$ \\
\hline Gipsy & 28 & $36.8 \%$ \\
\hline African & 8 & $10.5 \%$ \\
\hline Indian & 3 & $3.9 \%$ \\
\hline Age at menarche (years) & 13.0 & $12-14$ \\
\hline \multicolumn{3}{|l|}{ Menstrual cycles } \\
\hline Regular & 1 & $1.3 \%$ \\
\hline Irregular & 10 & $13.2 \%$ \\
\hline Oligomenorrhea & 49 & $64.5 \%$ \\
\hline Amenorrhea & 16 & $21.1 \%$ \\
\hline \multicolumn{3}{|l|}{ Infertility } \\
\hline Primary & 57 & $75.0 \%$ \\
\hline Secondary & 19 & $25.0 \%$ \\
\hline Concomitant factors & 14 & $18.4 \%$ \\
\hline Duration (months) & 40 & $27-64$ \\
\hline \multicolumn{3}{|l|}{ Obstetric history } \\
\hline Previous livebirth & 6 & $7.9 \%$ \\
\hline Previous spontaneous conception & 14 & $18.4 \%$ \\
\hline Current smoking & 18 & $23.7 \%$ \\
\hline Hypertension & 1 & $1.3 \%$ \\
\hline BMI $\left(\mathrm{kg} / \mathrm{m}^{2}\right)$ & 24.4 & $22.2-29.2$ \\
\hline Obesity & 15 & $19.7 \%$ \\
\hline Overweight & 21 & $27.6 \%$ \\
\hline Hyperandrogenism & 31 & $40.8 \%$ \\
\hline Clinic & 23 & $30.3 \%$ \\
\hline Biochemical (48) & 16 & $33.3 \%$ \\
\hline \multicolumn{3}{|l|}{ Hormonal characteristics $(50)$} \\
\hline LH (IU/L) & 4.6 & $3.6-6.6$ \\
\hline FSH (IU/L) & 8.2 & $4.9-12.0$ \\
\hline LH/FSH ratio & 2.0 & $1.1-2.7$ \\
\hline Estradiol (pg/nL) & 44.5 & $21.8-84.3$ \\
\hline \multicolumn{3}{|l|}{ Diabetes and hyperglycemia } \\
\hline Diabetes mellitus (42) & 0 & 0 \\
\hline Impaired fasting glucose (42) & 0 & 0 \\
\hline Impaired glucose tolerance (38) & 2 & $5.3 \%$ \\
\hline Dyslipidemia (43) & 31 & $72.1 \%$ \\
\hline Hypothyroidism (43) & 1 & $2.3 \%$ \\
\hline \multicolumn{3}{|l|}{ Ultrasound characteristics (51) } \\
\hline Mean ovarian volume $(\mathrm{mL})$ & 11.7 & $9.1-14.9$ \\
\hline
\end{tabular}

* Number of subjects analysed if observations not available for all cohort

sperm injection $(6 / 18 ; 33 \%)$. There was one case of ectopic pregnancy that occurred after spontaneous conception. Multiple pregnancy occurred in five pregnancies, one after ovulation induction with clomiphene citrate, one after intrauterine insemination and three after advanced reproductive techniques. In the group of patients without 


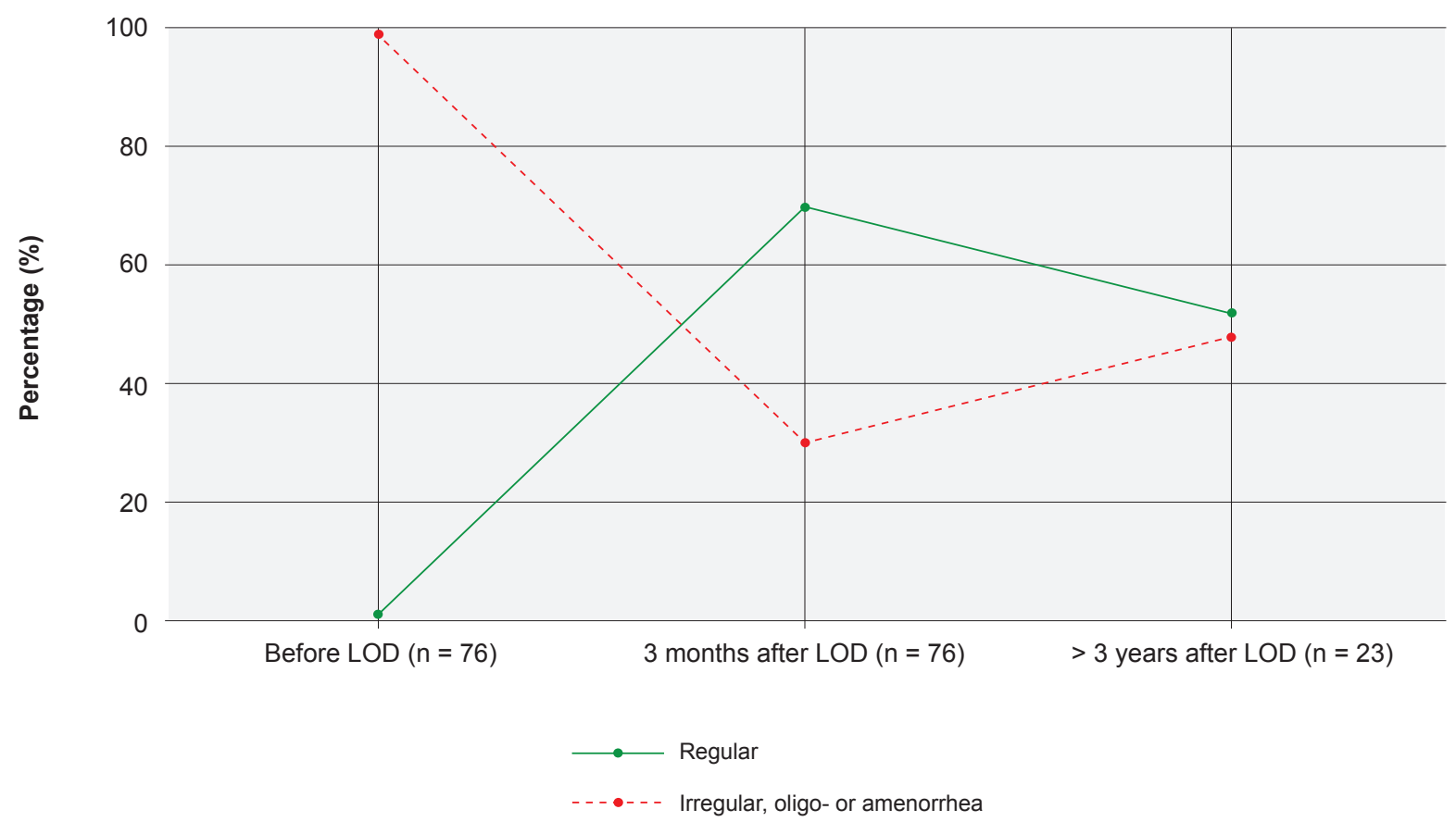

Figure 1 - Menstrual cycle characteristics before surgery, three months and more than three years after surgery

other concomitant infertility factors, a total of 45 women conceived (73\%) and 64 pregnancies were achieved of which 40 were spontaneous (63\%). Regarding the couples with other infertility factors, eight women conceived $(57 \%)$ and $46 \%$ of pregnancies were spontaneous (6/13).

Of all preoperative characteristics reviewed - including age, origin, age at menarche, menstrual cycles, type and duration of infertility, hyperandrogenism, LH/FSH ratio, $\mathrm{FSH}$, LH and estradio I levels, ovarian volume, presence of comorbidities associated with PCOS - the only prognostic factor that reached statistical significance was a shorter duration of infertility $(<3$ years) $(p<0.05$; OR $3.8-95 \%$ confidence interval $1.4-10.4)$.

\section{DISCUSSION}

Polycystic ovary syndrome is a common endocrine disorder and a frequent cause of infertility. The three main diagnostic features of PCOS are chronic anovulation, hyperandrogenism and polycystic ovaries, but other body systems may be affected causing complications as obesity, insulin resistance, diabetes and metabolic syndrome. Women with PCOS account for about $90 \%$ of the WHO class 2 (normogonadothrophic) anovulation, which is the most common category of anovulatory infertility. ${ }^{21}$ Menstrual disturbances are commonly observed in women with PCOS and up to $95 \%$ have oligomenorrhea or amenorrhea. ${ }^{22}$ In our cohort, only one patient had regular cycles, and $85 \%$ had oligo- or amenorrhea. About $60 \%-70 \%$ of women with PCOS have hirsutism and $15 \%-30 \%$ have acne..$^{2,3}$ In the current study one or both features were only present in $30 \%$, which may be related to the subjective nature of assessment of signs of clinical hyperandrogenism. Biochemical hyperandrogenism was not evaluated in all patients, but
$33 \%$ had high levels of serum free or total testosterone. Women with PCOS have an abnormal gonadotrophin secretion dynamics with an excessive secretion of $\mathrm{LH}$ and a normal secretion of $\mathrm{FSH}$. The $\mathrm{LH}$ to $\mathrm{FSH}$ ratio is therefore elevated in the early follicular phase. Although common, the absence of these changes does not exclude the diagnosis of PCOS. In our cohort, gonadotrophins were assessed in 50 cases, and in 25 (50\%), LH/FSH ratio was more than 2.

Laparoscopic ovarian diathermy is considered to be the second-line treatment in clomiphene citrate resistant infertile women. In the first report about this surgical technique, Gjønæss described an ovulation rate of $92 \%$ in three months and a pregnancy rate of $69 \% .{ }^{13}$ Over the years, retrospective, prospective and randomized controlled trials (RCTs) have established the efficacy of this procedure. A Cochrane systematic review and metaanalysis comparing LOD with other medical ovulation induction treatments confirmed that it was equally effective in terms of pregnancy, livebirth and miscarriage rates with a lower rate of multiple pregnancy. Overall, ovulation rates range from $40 \%$ to $86 \%$, pregnancy rates from $25 \%$ to $51 \%$ and livebirth rate per couple from $24 \%$ to $44 \% .{ }^{15}$ The same review compared results of unilateral and bilateral LOD and there were similar rates of livebirth, pregnancy, ovulation and miscarriage..$^{15}$ Ovulation was not evaluated in our study, but the significant increase in women with regular cycles after LOD (from 1 to $70 \%, p<0.01$ ) is an indirect indicator of ovulation improvement. Pregnancy rate was $70 \%$ and spontaneous pregnancy rate was $38 \%$, which is in agreement with the above quoted figures. A total of 77 pregnancies were achieved in our series, $60 \%$ of which were spontaneous and $14 \%$ were obtained after ovulation induction with clomiphene citrate $(7.8 \%)$ or gonadotrophins 
Table 2 - Reproductive outcomes in three periods of time regarding first pregnancy achieved after surgery and total number of pregnancies obtained during short- and long-term follow-up

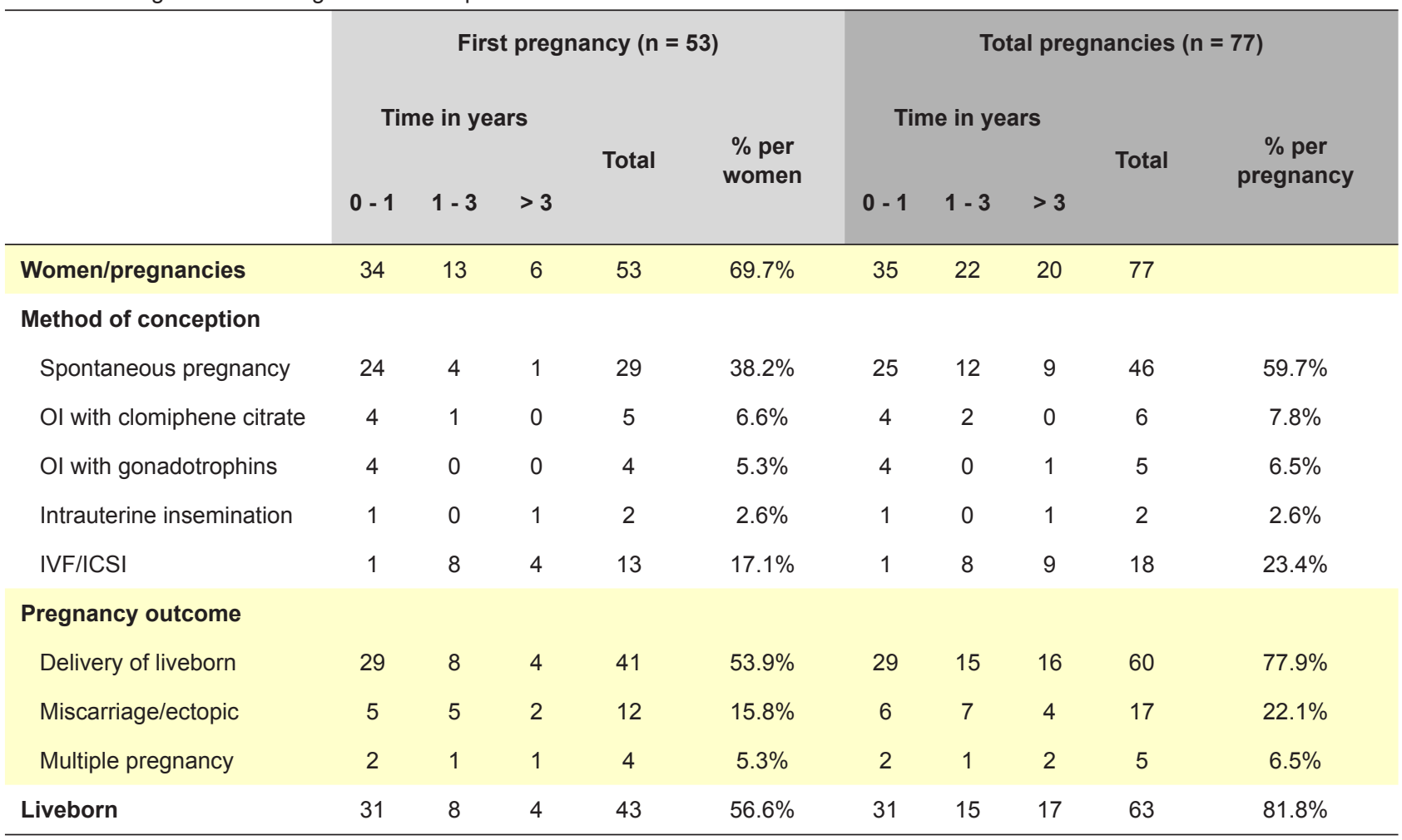

OI: Ovulation induction; IVF: In vitro fertilization; ICSI: Intracytoplasmic sperm injection.

(6.5\%). This is in agreement with other reports that LOD may increase ovary sensitivity to medical ovulation induction. ${ }^{23}$

Women with PCOS are believed to have a higher prevalence of early pregnancy loss with reported rates ranging from $30 \%$ to $50 \%$, but the effect of other confounding factors such as obesity or ovulation induction may explain the existing conflicting data. ${ }^{14,21}$ Laparoscopic ovary diathermy appears to be associated with a lower rate of miscarriage. Since hypersecretion of $\mathrm{LH}$ is suggested to be related to reproductive dysfunction and reduction in embryo survival, the decrease of LH plasma levels after surgery could explain the lower rates of miscarriage in LODtreated women. ${ }^{14,24}$ Notwithstanding, significant differences in miscarriage rates were not found when LOD was compared to other medical ovulation induction treatments. ${ }^{15}$ Miscarriage rate following LOD in our series was similar to the previously reported figures. ${ }^{25,26}$ Of the five multiple pregnancies reported in our cohort none occurred after spontaneous conception and their frequency was similar to what was previously described $(0 \%-10 \%) .{ }^{15}$

Laparoscopic ovarian diathermy is not a curative treatment for PCOS, but is associated with long-term beneficial effects. In a long-term follow-up study, Gjønnæss ascertained that ovulation still occurred in 23 out of 31 women (74\%), 10 to 20 years after LOD $^{27}$ Amer et al concluded that LOD is associated with a sustained improvement in menstrual regularity and reproductive function in about one-third of cases and that the beneficial decrease in $\mathrm{LH} /$ FSH ratio, $\mathrm{LH}$ and testosterone levels and the reduction in ovarian volume lasted up to nine years in most patients. ${ }^{17,28}$
In a questionnaire based study of 168 women 8 to 12 years after being randomized to receive LOD or ovulation induction with gonadotrophins, $54 \%$ of the LOD-treated women had regular menstrual cycles and had an increased chance of having a second child. ${ }^{29}$ Long-term follow-up of our cohort confirm that improvement in ovulation is sustained over time as demonstrated by the $52 \%$ of women that still had regular menstrual cycles after three to nine years. Although $45 \%$ of pregnancies occurred within the first year, $26 \%$ were achieved more than three years after surgery, suggesting a long lasting effect in fertility.

Advantages of laparoscopic ovarian diathermy when compared to gonadotrophin treatment go beyond similar success rates and lower multiple pregnancy risk. It does not require additional procedures or close monitoring, it is not associated with an increased risk of hyperstimulation syndrome and is more cost-effective. In addition, if offers the chance of recurrent ovulatory cycles that are usually monofollicular allowing women to conceive naturally. In our study, other advantage found was the opportunity to perform a diagnostic laparoscopy and chromotubation that is frequently undertaken in the initial evaluation of infertility and could therefore exclude other causes and also treat them simultaneously.

The procedure is considered to be simple and safe and in our study there was not any report of immediate or late complications. Nevertheless, as a surgical technique it may have its own complications, like damage to neighbouring pelvic and abdominal organs, infection, bleeding and anaesthesia-related side effects. Concerns about pelvic 
adhesion formation and excessive damage to the ovary should also be taken into account. Although the risk of pelvic adhesions formation has been reported to be lower after LOD than after the classic ovarian wedge resection, ${ }^{30}$ Mercorio et al in a prospective study of 90 women reported a $60 \%$ adhesion rate that was independent of the number of punctures and side. ${ }^{31}$ In our study, pelvic adhesion formation was not investigated posteriorly. Regardless the scarcity of available data, there is no evidence of premature ovarian failure after employment of the correct technique ${ }^{32,33}$ and only one case report of ovarian atrophy following high-energy drilling (10 times more than usual, i.e. eight coagulation points at $400 \mathrm{~W}$, for $5 \mathrm{~s}$ ) has been published in the literature. ${ }^{34}$ In our cohort only one woman did not resume menstrual cycles after surgery and continue to have amenorrhea for more than eight years. This patient conceived after ovulation induction with gonadotrophins and did not report any menopausal symptoms. Further evaluation of ovarian reserve was not undertaken in the current study.

Although response rate is encouraging, failure to respond occurs and its cause is frequently uncertain. Therefore, identifying pretreatment clinical, biochemical and/or ultrasonographic features associated with improved ovulation and pregnancy rates could help select the group of infertile women with PCOS more likely to benefit from surgery and avoid unnecessary procedures. In our study, only infertility duration less than three years was correlated with improved spontaneous pregnancy rates, meaning that no other preoperative feature were useful. Other studies found that in addition to infertility duration, age, BMI and preoperative hormone levels may help predict outcomes. ${ }^{35-38}$ A systematic review and meta-analysis comparing reproductive outcomes in obese and lean PCOS patients after ovarian ablative therapy confirmed that ovulation and pregnancy rates were higher if BMI $<25 \mathrm{~kg} /$ $\mathrm{m}^{2}{ }^{39}$ In our cohort, almost half women were overweight or obese, but this was not found to have a significant impact. In fact, BMI, infertility duration and age may also influence on reproductive outcomes in the general population. Regarding preoperative hormone levels, Abuelghar et al. in a prospective study concluded that higher preoperative levels of LH, FSH and/or androstenedione were associated with higher rates of spontaneous ovulation within the first 8 weeks after LOD, but only $\mathrm{FSH}$ and androstenedione were independent predictive factors of success. ${ }^{40}$ Two small prospective studies found that a higher plasma level of anti-Müllerian hormone before surgery could be an useful predictor of no ovulation after LOD. ${ }^{41,42}$ In our study, most of these factors found to be useful predictors were not available in all patients or were not analysed. Finding predictive factors would definitely help with counselling of the couples, but studies often find different factors which may be explained by the difference in measured outcomes and follow-up duration.
Limitations of our study relate to its retrospective nature and relatively small sample size. Heterogeneity within our cohort regarding ethnicity, type of infertility, presence of concomitant infertility factors and history of previous treatments may have resulted in bias. Evaluation of biochemical hyperandrogenism and ultrasonographic objective measure of ovarian volume were not available in all patients hindering assessment of the full expression of PCOS. Also, lack of information about hypothalamicpituitary axis function, diabetes and insulin resistance, dyslipidemia and thyroid function in some patients restricted baseline characterization of the whole cohort and identification of preoperative predictive factors. The absence of a postoperative laboratory assessment of spontaneous ovulation and the lack of evaluation of the endocrine profile change after LOD restricted evaluation of success to pregnancy rate, which in turn is the most important fact to the couple.

\section{CONCLUSION}

Laparoscopic ovarian diathermy is a safe and effective second line treatment for anovulatory infertile women with PCOS who failed to respond to ovulation induction with clomiphene citrate. Surgery is a particularly good option for those women who have other indication for laparoscopy and those who live far away from the fertility centres in which close surveillance for ovulation induction with gonadotrophins is burdensome. Results of this study are encouraging and show short as well as long-term benefits regarding fertility and menstrual cycle regularity. Achievement of a pregnancy rate similar to other studies helps counselling couples seeking infertility treatment in our centre. Only infertility duration was found to be correlated to improved spontaneous pregnancy rates.

\section{ACKNOWLEDGMENTS}

The authors thank Susana Pereira for her contribution to this article.

\section{PROTECTION OF HUMANS AND ANIMALS}

The authors declare that the procedures were followed according to the regulations established by the Clinical Research and Ethics Committee and to the Helsinki Declaration of the World Medical Association.

\section{DATA CONFIDENTIALITY}

The authors declare having followed the protocols in use at their working center regarding patient's data publication.

\section{CONFLICTS OF INTEREST}

The authors declare that there are no conflicts of interest.

\section{FUNDING SOURCES:}

No subsidies or grants contributed to this work. 


\section{REFERENCES}

1. The Rotterdam ESHRE/ASRM-Sponsored PCOS Consensus Workshop. Revised 2003 consensus on diagnostic criteria and longterm health risks related to polycystic ovary syndrome. Fertil Steril. 2004;81:19-25.

2. Norman RJ, Dewailly D, Legro RS, Hickey TE. Polycystic ovary syndrome. Lancet. 2007;370:685-97.

3. Sirmans SM, Pate KA. Epidemiology, diagnosis, and management of polycystic ovary syndrome. Clin Epidemiol. 2014;6:1-13.

4. Azziz R, Woods KS, Reyna R, Key TJ, Knochenhauer ES, Yildiz BO. The prevalence and features of the polycystic ovary syndrome in an unselected population. J Clin Endocrinol Metab. 2004;89:2745-9.

5. Asunción M, Calvo RM, Millán JL, Sancho J, Avila S, Escobar-Morreale HF. A prospective study of the prevalence of the polycystic ovary syndrome in unselected caucasian women from Spain. J Clin Endocrinol Metab. 2000;85:2434-8.

6. Kousta E, White DM, Cela E, Mccarthy MI, Franks S. The prevalence of polycystic ovaries in women with infertility. Hum Reprod. 1999;14:2720 3.

7. Broekmans FJ, Knauff E, Valkenburg O, Laven JS, Eijkemans MJ, Fauser BC. PCOS according to the Rotterdam consensus criteria: Change in prevalence among $\mathrm{WHO}-\mathrm{Il}$ anovulation and association with metabolic factors. BJOG. 2006;113:1210-7.

8. Berger J, Bates G. Optimal management of subfertility in polycystic ovary syndrome. Int J Womens Health. 2014;6:613-21.

9. Costello MF, Misso ML, Wong J, Hart R, Rombauts L, Melder A, et al. The treatment of infertility in polycystic ovary syndrome: a brief update. Aust N Z J Obstet Gynaecol. 2012;52:400-3.

10. Abu Hashim H. Clomiphene citrate alternatives for the initial management of polycystic ovary syndrome: an evidence-based approach. Arch Gynecol Obstet. 2012;285:1737-45.

11. Legro R, Brzyski R, Diamond M, Coutifaris C, Schlaff W, Casson P et al. Letrozole versus clomiphene for infertility in the polycystic ovary syndrome. N Engl J Med. 2014;371:119-29.

12. Costello MF, Ledger WL. Evidence-based management of infertility in women with polycystic ovary syndrome using surgery or assisted reproductive technology. Womens Health. 2012;8:291-300.

13. Gjonnaess $H$. Polycystic ovarian syndrome treated by ovarian electrocautery through the laparoscope. Fertil Steril. 1984;41:20-5.

14. Pirwany I, Tulandi T. Laparoscopic treatment of polycystic ovaries: is it time to relinquish the procedure? Fertil Steril. 2003;80:241-51.

15. Farquhar C, Brown J, Marjoribanks J. Laparoscopic drilling by diathermy or laser for ovulation induction in anovulatory polycystic ovary syndrome. Cochrane Database Syst Rev. 2012: CD001122.

16. Farquhar CM, Williamson K, Brown PM, Garland J. An economic evaluation of laparoscopic ovarian diathermy versus gonadotrophin therapy for women with clomiphene citrate resistant polycystic ovary syndrome. Hum Reprod. 2004;19:1110-5.

17. Amer SA, Gopalan V, Li TC, Ledger WL, Cooke ID, Sheffield S. Long term follow-up of patients with polycystic ovarian syndrome after laparoscopic ovarian drilling : clinical outcome. Hum Reprod. 2002;17:2035-42.

18. Mohiuddin S, Bessellink D, Farquhar C. Long-term follow up of women with laparoscopic ovarian diathermy for women with clomipheneresistant polycystic ovarian syndrome. Aust N Z J Obstet Gynaecol. 2007;47:508-11.

19. World Health Organization. Obesity: preventing and managing the global epidemic. Report of a WHO Consultation. World Health Organ Tech Rep Ser. 2000;894:1-253.

20. World Health Organization. Definition and diagnosis of diabetes mellitus and intermediate hyperglycemia - report of a WHO/IFD consultation. Geneva: WHO; 2006.

21. ESHRE Capri Workshop Group. Health and fertility in World Health Organization group 2 anovulatory women. Hum Reprod Update. 2012;18:586-99.

22. Fauser BC, Tarlatzis BC, Rebar RW, Legro RS, Balen AH, Lobo R, et al. Consensus on women's health aspects of polycystic ovary syndrome (PCOS): the Amsterdam ESHRE/ASRM-Sponsored 3rd PCOS Consensus Workshop Group. Fertil Steril. 2012;97:28-38.
23. Abu Hashim H, El-Shafei M, Badawy A, Wafa A, Zaglol H. Does laparoscopic ovarian diathermy change clomiphene-resistant PCOS into clomiphene-sensitive? Arch Gynecol Obstet. 2011;284:503-7.

24. Van der Spuy ZM, Dyer SJ. The pathogenesis of infertility and early pregnancy loss in polycystic ovary syndrome. Best Pract Res Clin Obstet Gynaecol. 2004;18:755-71.

25. Amer SA, Li TC, Metwally M, Emarh M, Ledger WL. Randomized controlled trial comparing laparoscopic ovarian diathermy with clomiphene citrate as a first-line method of ovulation induction in women with polycystic ovary syndrome. Hum Reprod. 2009;24:219-25.

26. Abu Hashim H, El Lakany N, Sherief L. Combined metformin and clomiphene citrate versus laparoscopic ovarian diathermy for ovulation induction in clomiphene-resistant women with polycystic ovary syndrome: a randomized controlled trial. J Obstet Gynaecol Res. 2011;37:169-77.

27. Gjønnæss H. Late endocrine effects of ovarian electrocautery in women with polycystic ovary syndrome. Fertil Steril. 1998;69:697-701.

28. Amer SA, Banu Z, Li TC, Cooke ID. Long-term follow-up of patients with polycystic ovary syndrome after laparoscopic ovarian drilling: endocrine and ultrasonographic outcomes. Hum Reprod. 2002;17:2851-7.

29. Nahuis MJ, Kose N, Bayram N, van Dessel HJ, Braat DD, Hamilton CJ et al. Long-term outcomes in women with polycystic ovary syndrome initially randomized to receive laparoscopic electrocautery of the ovaries or ovulation induction with gonadotrophins. Hum Reprod. 2011;26:1899_ 904

30. Campo S. Ovulatory cycles, pregnancy outcome and complications after surgical treatment of polycystic ovary syndrome. Obstet Gynecol Surv. 1998:53:297-308.

31. Mercorio F, Mercorio A, Di Spiezio Sardo A, Barba GV, Pellicano M, Napp C. Evaluation of ovarian adhesion formation after laparoscopic ovarian drilling by second-look minilaparoscopy. Fertil Steril. 2008;89:1229-33.

32. Api M. Is ovarian reserve diminished after laparoscopic ovarian drilling? Gynecol Endocrinol. 2009;25:159-65.

33. Farzadi L, Nouri M, Ghojazadeh M, Mohiti M, Aghadavod E. Evaluation of ovarian reserve after laparoscopic surgery in patients with polycystic ovary syndrome. Bioimpacts. 2012;2:167-70.

34. Dabirashrafi $\mathrm{H}$. Complications of laparoscopic ovarian cauterization Fertil Steril. 1989;52:878-9.

35. Hashim HA. Predictors of success of laparoscopic ovarian drilling in women with polycystic ovary syndrome: an evidence- based approach. Arch Gynecol Obs. 2015;29:11-8.

36. Amer SA, Li TC, Ledger WL. Ovulation induction using laparoscopic ovarian drilling in women with polycystic ovarian syndrome: predictors of success. Hum Reprod. 2004;19:1719-24.

37. Munir SS, Amin D, Sultana M, Saeed T. Ovulation Induction using laparoscopic ovarian drilling in women with polycystic ovarian syndrome: predictors of success. Biomedica. 2010;26:130-4.

38. Palomba S, Falbo A, Orio F Jr, Russo T, Sbano F, D'Alessandro $P$, et al. Efficacy of laparoscopic ovarian diathermy in clomiphene citrateresistant women with polycystic ovary syndrome: relationships with chronological and ovarian age. Gynecol Endocrinol. 2006;22:329-35.

39. Baghdadi LR, Abu Hashim H, Amer SA, Palomba S, Falbo A, Al-Ojaimi E et al. Impact of obesity on reproductive outcomes after ovarian ablative therapy in PCOS: a collaborative meta-analysis. Reprod Biomed Online. 2012;25:227-41.

40. Abuelghar WM, Bayoumy HA, Ellaithy MI, Khalil MS. Women with clomiphene citrate resistant polycystic ovarian disease: predictors of spontaneous ovulation after laparoscopic ovarian drilling. Eur J Obstet Gynecol Reprod Biol. 2014;175:178-85.

41. Amer SA, Li TC, Ledger WL. The value of measuring anti-Mullerian hormone in women with anovulatory polycystic ovary syndrome undergoing laparoscopic ovarian diathermy. Hum Reprod. 2009;24:2760-6.

42. Elmashad Al. Impact of laparoscopic ovarian drilling on anti-Müllerian hormone levels and ovarian stromal blood flow using three-dimensional power Doppler in women with anovulatory polycystic ovary syndrome. Fertil Steril. 2011;95:2342-6. 